\title{
A qualitative study examining methods of accessing and identifying research relevant to clinical practice among rehabilitation clinicians
}

This article was published in the following Dove Press journal: Journal of Multidisciplinary Healthcare

\author{
Drasti Patel' \\ Christine Koehmstedt ${ }^{1}$ \\ Rebecca Jones' \\ Nathan T Coffey' \\ Xinsheng Cai ${ }^{2}$ \\ Steven Garfinkel ${ }^{2}$ \\ Dahlia M Shaewitz ${ }^{2}$ \\ Ali A Weinstein' \\ 'Center for Study of Chronic Illness \\ and Disability, College of Health \\ and Human Services, George Mason \\ University, Fairfax, VA, ${ }^{2}$ American \\ Institutes for Research, Washington, \\ DC, USA
}

\begin{abstract}
Purpose: Research examining the utilization of evidence-based practice (EBP) specifically among rehabilitation clinicians is limited. The objective of this study was to examine how various rehabilitative clinicians including physical therapists, occupational therapists, rehabilitation counselors, and physiatrists are gaining access to literature and whether they are able to implement the available research into practice.
\end{abstract}

Methods: A total of 21 total clinicians were interviewed via telephone. Using NVivo, a qualitative analysis of the responses was performed.

Results: There were similarities found with respect to the information-seeking behaviors and translation of research across the different clinician types. Lack of time was reported to be a barrier for both access to literature and implementation of research across all clinician types. The majority of clinicians who reported having difficulty with utilizing the published literature indicated that the literature was not applicable to their practice, the research was not specific enough to be put into practice, or the research found was too outdated to be relevant. In addition, having a supportive work environment aided in the search and utilization of research through providing resources central to assisting clinicians in gaining access to health information.

Conclusion: Our study identified several barriers that affect EBP for rehabilitation clinicians. The findings suggest the need for researchers to ensure that their work is applicable and specific to clinical practice for implementation to occur.

Keywords: health information, information behavior, knowledge utilization, research access

\section{Background}

The implementation of evidence-based practice (EBP) by health care providers has resulted in increased research about the information-seeking behaviors and information needs of clinicians. ${ }^{1-4}$ EBP enables clinicians to deliver quality care to improve patient outcomes upon successful translation of knowledge into clinical protocols and guidelines. ${ }^{5}$ While all medical professionals have been called to implement EBP into practice, the implementation of EBP remains slower for rehabilitation clinicians. ${ }^{6-9}$ In addition, within the field of rehabilitation, there is a gap between the evidence available in the literature and current standards of clinical practice. Therefore, a tension exists for rehabilitation clinicians: whether to utilize current standards (that may lack systematic evidence) or utilize the existing literature (that may not have a solution for the problem). ${ }^{10}$

A large body of the existing EBP literature focuses on individual clinician types, predominantly physical therapists (PTs) and occupational therapists (OTs), that are
Correspondence: Ali A Weinstein Center for Study of Chronic Illness and Disability, College of Health and Human Services, George Mason University, 4400 University Drive, MSN 2G7, Fairfax, VA 22030, USA

Tel +I 7039939632

Fax + I 7039932695

Email aweinst2@gmu.edu 
not necessarily within the field of rehabilitation. ${ }^{11,12}$ Rehabilitation clinicians are certified professionals who strive to improve the functionality and independence of individuals with disability. These clinicians often have differing levels of professional education (i.e., doctoral, master's, bachelor's) and work in varied settings, but require interdisciplinary participation with other health professionals within the same field to provide patients with an optimal level of care. ${ }^{5}$ For this reason, the ability to implement EBP must be observed among various types of rehabilitation professionals.

The limited published literature about EBP in clinical rehabilitation professionals has focused on the information-seeking behavior of PTs and OTs and, to a lesser extent, of speechlanguage pathologists, dieticians, and other counselors., ${ }^{3,6}$

These prior studies that involved PTs and OTs focused on their information-seeking behaviors and furthermore showed that these particular clinicians valued information from fellow colleagues or past clinical experience the most. ${ }^{8,11,13} \mathrm{~A}$ study of PTs, OTs, and other health professionals found that well over half of these types of clinicians utilized Internet search engines but still relied most heavily on colleagues and peers as their primary information source. ${ }^{13}$

Lack of time is the most commonly cited barrier to implementing EBP among PTs and OTs. ${ }^{11-15}$ Other barriers that have been reported include lack of research skills and lack of access. ${ }^{11,16-18}$ In a systematic review examining OTs' attitudes toward knowledge of and implementation of EBP, the primary barriers were time, skills, and the applicability of research findings into clinical practice. ${ }^{15} \mathrm{~A}$ previous research specifically examining information-seeking behaviors has found accessibility to be the determining factor for the decision maker's source of information. ${ }^{19}$

While there is a growing body of literature examining EBPs and research preferences of PTs and OTs, research examining the information-seeking behavior and implementation of research findings of other clinicians, particularly in the realm of rehabilitation, is still sparse..$^{10}$ In addition, to the best of our knowledge, there are no studies that examine the preferred information sources and perceived applicability of research findings among rehabilitation professionals together, which include the full range of the rehabilitation team: physiatrists, PTs, OTs, and rehabilitation counselors (RCs). This study focused on investigating the information needs and behaviors of rehabilitation clinicians and identifying barriers to EBP. Two main research questions drove this investigation: 1) How do rehabilitation clinicians access the research literature? and 2) Are rehabilitation clinicians able to find literature that is applicable to their clinical practice?

\section{Methods}

\section{Participants}

Clinicians were recruited through email listservs via professional organizations and flyers. Specifically, National Institute on Disability, Independent Living, and Rehabilitation Research (NIDILRR)-funded spinal cord injury (SCI), traumatic brain injury (TBI), and Burn Model Systems grantees were contacted to recruit participants. Subjects were also solicited through advertisements placed in printed materials, websites, and social media sites and through recruitment messages sent via email to rehabilitation-focused hospitals.

A total of 21 clinicians were interviewed - seven PTs, five OTs, four physiatrists, and five RCs. In order to be eligible to participate, participants had to be a PT, OT, physiatrist, or RC who currently treat individuals with SCI, TBI, and/or burn injury. A PT was defined as an individual who had earned a graduate level degree from an accredited PT program and passed a state-administered national exam (licensed). An OT was defined as an individual who had completed a master's program in occupational therapy and passed the National Board for Certification in Occupational Therapy exam (licensed). A physiatrist was defined as a boardcertified physical medicine and rehabilitation physician. An $\mathrm{RC}$ was defined as an individual with certification from the Commission on Rehabilitation Counselor Certification and was licensed by his or her state. ${ }^{20} \mathrm{RCs}$ provide counseling to individuals with disabilities to help them achieve their personal, career, and independent living goals. We began conducting interviews in August 2015 and completed all the interviews by December 2015. Our recruitment strategy involved collecting equivalent numbers of PTs, OTs, physiatrists, and RCs. We stopped recruitment when saturation had been reached (no new areas were emerging in interviews across the different clinician types).

All participants provided oral informed consent prior to participating in phone interviews as approved through the institutional review boards of the American Institutes for Research (AIR) and George Mason University. Phone interviews were conducted to allow for geographic variability among participants. The study population's mean age was $43.4 \pm 10.5$ years, and the majority of clinicians interviewed were females (81\%). Detailed demographic information on the participants can be found in Table 1 .

\section{Data collection}

As commonly utilized in the realm of qualitative research, ${ }^{21}$ semi-structured interviews were conducted in order to obtain a more thorough understanding of the health information 
needs of rehabilitation clinicians. Duration of the interviews ranged from 17 minutes and 6 seconds to 35 minutes and 13 seconds, with the average phone call lasting 22 minutes and 22 seconds. All interviews were tape recorded, and the researcher leading the call took notes during each interview session. Analysis was conducted on participant's response to seven open-ended questions, which were developed by the investigators. The open-ended questions are presented in Table 2. Respondents were compensated for participation in the interview.

\section{Data analysis}

Prior to performing the analysis on participants' responses, the research team familiarized themselves with the interviews by listening to the recordings and reviewing notes taken by the interviewers during the interviews in order to develop a bank of qualitative answers and themes based on responses given to the open-ended questions. ${ }^{22}$ The bank of answers and themes were used to code the interviews (organizing the material into related segments). ${ }^{23}$ Then, a random selection of the interviews $(n=9)$ that included a combination of all clinician types was performed. These audio recordings were analyzed using the framework approach. ${ }^{24}$ This approach is within the broad family of analysis methods often termed as thematic analysis or qualitative content analysis. We used this type of analysis to draw descriptive or explanatory conclusions clustered around themes, while allowing the ability to analyze the data across individuals. Upon refining the draft answer bank and themes, two researchers coded the same interview independently to determine the reliability of the coding scheme across coders and to ensure that coding was completed in a comparable manner. The two researchers met

Table I Study participants' characteristics

\begin{tabular}{|c|c|c|c|c|c|c|c|}
\hline $\begin{array}{l}\text { Participant } \\
\text { ID }\end{array}$ & $\begin{array}{l}\text { Clinician } \\
\text { type }\end{array}$ & $\begin{array}{l}\text { Age } \\
\text { (years) }\end{array}$ & Gender & $\begin{array}{l}\text { Highest } \\
\text { degree } \\
\text { earned }\end{array}$ & $\begin{array}{l}\text { Years in } \\
\text { practice }\end{array}$ & $\begin{array}{l}\text { Amount of time } \\
\text { spent in patient } \\
\text { care }(\%)\end{array}$ & $\begin{array}{l}\text { Amount of } \\
\text { time spent in } \\
\text { research (\%) }\end{array}$ \\
\hline 5000 & $\mathrm{RC}$ & 55 & Female & Master's & 31 & $50-75$ & $25-49$ \\
\hline 5001 & $\mathrm{RC}$ & 39 & Female & Master's & 14 & $75-100$ & $<25$ \\
\hline 5003 & $\mathrm{RC}$ & 49 & Female & Master's & 25 & $75-100$ & $<25$ \\
\hline 5004 & $\mathrm{PT}$ & 32 & Female & Doctorate & 8 & $50-74$ & $<25$ \\
\hline 5005 & Physiatrist & 53 & Male & MD & 23 & $25-49$ & $<25$ \\
\hline 5006 & $\mathrm{RC}$ & 44 & Female & Master's & 18 & $50-74$ & $<25$ \\
\hline 5007 & OT & 57 & Female & Master's & 20 & $<25$ & $50-74$ \\
\hline 5009 & OT & 27 & Female & Master's & 3 & $50-74$ & $<25$ \\
\hline 5010 & OT & 28 & Female & Master's & 4 & $75-100$ & $<25$ \\
\hline 5012 & PT & 32 & Female & Master's & 8 & $50-74$ & $<35$ \\
\hline 5013 & PT & 32 & Female & Doctorate & 5 & $75-100$ & $<25$ \\
\hline 5014 & PT & 38 & Female & Doctorate & 12 & $50-74$ & $<25$ \\
\hline 5015 & PT & 45 & Female & Bachelor's & 24 & $75-100$ & $25-49$ \\
\hline 5016 & OT & 54 & Female & Master's & 30 & $<25$ & $<25$ \\
\hline 5018 & Physiatrist & 40 & Male & MD & 5 & $50-74$ & $<25$ \\
\hline 5020 & Physiatrist & 44 & Male & MD & 14 & $50-74$ & $<25$ \\
\hline 5021 & Physiatrist & 43 & Male & MD & 12 & $75-100$ & $<25$ \\
\hline 5023 & $\mathrm{PT}$ & 36 & Female & Master's & 10 & $50-74$ & $<25$ \\
\hline 5024 & OT & 54 & Female & Bachelor's & 30 & $50-74$ & $<25$ \\
\hline 5025 & $\mathrm{PT}$ & 43 & Female & Bachelor's & 20 & $50-74$ & $<25$ \\
\hline 5026 & $\mathrm{RC}$ & 66 & Female & Bachelor's & 22 & $75-100$ & $<25$ \\
\hline
\end{tabular}

Abbreviations: RC, rehabilitation counselor; MD, Doctor of Medicine; PT, physical therapist; OT, occupational therapist.

Table 2 Open-ended question prompts

I. What are the sources of information that you use when determining a treatment plan for a patient?

2. What role do published research findings play in your practice?

3. Are these types of research that you are more likely to utilize than others, such as clinical trials or systematic reviews of literature?

4. What types of sources do you use to access research findings?

5. How easy or difficult is it for you to get hold of research information to assist you in making decisions about your practice? If there are difficulties what are the main problems?

6. In what ways has published research changed or influenced your practice? Can you think of a specific instance?

7. What problems do you think rehabilitation clinicians face in trying to implement research findings into practice? 
afterward to discuss discrepancies in coding and determine working definitions to ensure that both individuals were interpreting codes similarly. These two researchers went on to code the interviews for all participants. All 21 interviews were included in the final analyses, including the nine that were used to create the bank of answers and themes.

The coding process using NVivo was divided into two stages. NVivo is a qualitative data analysis computer software package that has been designed to help organize and analyze nonnumerical data. It allows users to classify, sort, and arrange information, thereby examining relationships in the data. First, the researchers coded participants' direct answers to each open-ended question. Then, the interviewers coded the interviews for a second time to identify themes. There were instances when a participant's response fell beyond the scope of the answer bank. In this case, a code was added to the answer bank and the remaining research team members were notified of the change. In total, five new codes were added during the coding process. Overall, seven overarching themes were identified (in addition to content answers to the questions): assistance accessing information, lack of access to the literature, lack of useful information in the literature, seeking efficiency to understanding the literature, supportive work environment and its impact on accessing/ utilizing information, time constraints, and the specific usage of medical literature.

Qualitative data from the participants' open-ended responses were coded using NVivo 10 for Mac. Of the 21 interviews analyzed using the two-stage process, one interview was partially analyzed due to poor quality of the audio file. The NVivo for Mac data file was then converted to the $\mathrm{PC}$ version of NVivo 10 in order to use the enhanced data analysis features. Using the PC version of NVivo 10, the frequencies of each code were exported to Microsoft Excel. Using Microsoft Excel, the frequencies were first used to calculate the percentage of all clinicians who responded to each code, followed by identification of the trends, which are presented in the "Results" section.

\section{Results}

Study participants responded to open-ended questions about their current health information sources and implementation of EBP. There were no systematic differences identified across clinician types with themes.

\section{Information sources}

Clinicians reported a variety of sources when developing a treatment plan. In all, 12 of the 21 clinicians indicated that published research played an "important role" in their practice. The majority of clinicians $(n=13)$ said that they were most likely to use systematic reviews when available.

I think clinical trials are what I use in my treatment plan. When I am making recommendations to my patients about their future care, then I will more likely use systematic reviews to let them know all of the different options. [Interview 5004: PT]

Usually I like to see topic reviews by experts in the field. I like to see randomized control trials but we don't have many in spinal cord injury. Systematic reviews are okay. [Interview 5018: physiatrist]

Clinical trials were a highly sought after source of information noted by the respondents. Of the clinicians interviewed, eight reportedly used clinical trials to gather evidence for use in their practice.

We tend to want more clinical trials, but if they are not available, then we take anything we can get so we'll use the other options. But those are the [gold standard] that we like to use - randomized control trials, but those are not always available. [Interview 5014: PT]

Many clinicians rely heavily on their peers for support in making clinical decisions and developing treatment plans. Over one-third $(n=8)$ of the interviewed clinicians cited "external feedback from colleagues" as their primary information source.

I rely on the expertise and opinions of my attending physicians, on the opinion of the occupational therapists, and on my own experience. [Interview 5026: RC]

Other sources included "prior clinical experience" as their primary source of information when forming a treatment plan.

Most of [my decisions are] based on clinical experience. I have been there 21 years. Other coworkers have also been there probably 30 years so a lot is clinically based. Just in recent years, I think research is trying to return to get more evidence-based practice, but there is just not enough. I think it's just a specialty area that it's a small quantity of people who are doing burn care even have the knowledge to want to do research. It's such a few that not a lot of it gets done. [Interview 5025: PT]

\section{Facilitators for accessing literature}

Clinicians were also asked how difficult it was for them to obtain research information and to specify any problems 
they faced accessing it. Only one-third $(n=8)$ of clinicians stated that they faced "little to no difficulty" when trying to get hold of literature. Many of the clinicians reported relying on a supportive work environment to aid with accessing the literature $(n=8)$. A supportive work environment was described by the rehabilitation clinicians as having access to evidence-based literature through various services. Many had access through subscriptions to professional organizations, access to librarian services that performed literature searches for them, or subscriptions to relevant medical journals.

I use the journals I subscribe to, which are a couple of neurology journals, a couple of physical therapy journals, and brain injury association journals. I also use information from any continuing courses I attend at Boston. We also have pretty frequent resources in services in our department as well. So it's really easy to kind of access any new information through that. [Interview 5004: PT]

We had wonderful resources at the NIH. We had a library and I had set up my National Center for Biotechnology Information (NCBI) [account] - but you can put in an automatic library search for certain key words. I would get a weekly synopsis of the latest research of that as a key word. [Interview 5007: OT]

I would actually use our librarian to look up articles, in a medical library. I've also used my grad student account to go on PubMed. And we have [...] a journal of the American Occupational Therapy Association [participant is a member], so I'll use that. [Interview 5010: OT]

\section{Barriers to accessing the literature and implementing EBP}

The majority of clinicians reported time as a major constraint to utilization of literature $(n=13)$. The participants who indicated time as a major barrier described this barrier in two different ways. Of these two time barriers, the one identified in the previous literature was not having time to search for relevant literature. The second time constraint that emerged was that there was no time to integrate the relevant research findings into their clinical practice. Research protocols are implemented with clear start and ending points, along with structured indications for the amount of time that should be spent with patients in particular activities/treatments. However, these structured time points and the length of interventions are sometimes not feasible in a clinical environment.

There's not really time set aside to look for research or reasons why we do things [...]. There's really not a set out time for research. There's barely enough time to come up with a treatment plan versus research why you're doing that. It's just a fast-paced environment so there's not time to sit at a computer. [Interview 5009: OT]

The patient load is so much that it doesn't allow to give extra time in researching and deeper insights in how rehabilitation can be done. [Interview 5003: RC]

The research studies have people for months and months and months doing the same thing or the data is taken over a few years, and we see people for 6 weeks at most. To get a good indication of whether something is working or something's not working, it may need more time, it may need less time. We just don't really know because we don't see always people for as long as the research indicates.

[Interview 5009: OT]

Another common barrier that emerged was that the research did not include specificity on the treatment parameters $(n=6)$. The participants were not able to apply the evidence from the literature since there was a lack of evidence on the specific medical conditions and comorbidities that are seen in clinical practice $(n=5)$.

I think most research uses patients in chronic stages of disease and we deal with patients who are in acute stages of disease. Also, the intensity that the exercises are prescribed for 2-3 hours a day is much more than we can offer in patient rehabilitation as well as some of the types of equipment that is used. Robotics is being studied a lot now and that is not accessible. We have maybe one unit in our hospital but that is not accessible to every patient for an hour or two a day. We end up having to use more manual skills and things like that. [Interview 5004: PT].

It is easy for me to access the research that exists. A lot of times, the difficulty is that there may not have been a study on the particular question that I have to find. [Interview 5020: physiatrist]

Sometimes you read studies and they're done using certain equipment that I don't have access to. [5012: PT]

I would say that I generally don't find an awful a lot that's relevant. I do something pretty specific in vocational evaluations. And I wouldn't say that I find there's a tremendous amount of research available to use. [Interview 5001: RC]

\section{Discussion}

The purpose of this study was to understand the informationseeking behavior of rehabilitation clinicians and to determine the usefulness of this literature to their clinical practice. To our knowledge, this study was the first to evaluate these 
objectives across various rehabilitation clinician specialties, including PTs, OTs, RCs, and physiatrists. Clinicians were asked about how they currently access literature, what their main sources of information were, and to identify specific barriers that may be hindering implementation of evidencebased literature.

Consistent with published literature on other health professionals, ${ }^{11-15}$ our study found that time constraints are a major barrier preventing rehabilitation clinicians from implementing evidence-based research. The majority of prior rehabilitation literature indicated PTs to have time constraints as a barrier. This qualitative study reveals this same barrier across other rehabilitation clinician types, including OTs, physiatrists, and RCs.

Unique to our study was the identification of two distinct categories of time constraints. One was the lack of time to research evidence based-literature. This was more pronounced among rehabilitation clinicians who did not discuss a supportive work environment. The second time constraint was that even though rehabilitation clinicians perceived research as being important to their practice, the research obtained could not be applied to their daily practice due to lack of time to implement research findings. Other common barriers rehabilitation clinicians faced were lack of applicability of research, feeling research was outdated, and insufficient detailed information in research findings.

A supportive work environment was a reoccurring theme among the rehabilitation clinicians, with the presence of a supportive work environment aiding in the search and utilization of research. Specific resources that were helpful included library services (i.e., a librarian to assist in a literature search) and work-supported professional memberships (which included journal memberships). In previous research on PTs, these supportive work environment factors were also related to search and utilization of literature behaviors. ${ }^{25}$

The interviews also uncovered preferred sources of health information. Systematic reviews and clinical trials were the most useful sources for integrating the research literature into practice. Similar to previous literature, we also found that Internet sources, mainly in the form of health-related databases like PubMed, were a popular information source among rehabilitation clinicians. ${ }^{13}$ The rehabilitation literature has begun to recognize the need for knowledge translation tools to be available for researchers to help clinicians translate and integrate findings into clinical practice. ${ }^{26,27}$

The clinicians interviewed mentioned that rehabilitation information published in journals can be outdated, unspecific, or not applicable to their particular area of practice. The lack of applicability of research findings was linked to the shorter length of patient follow-up than what is indicated in the literature and also a lack of access to equipment that is utilized in research settings. To address these issues, future research should consider utility in a clinical setting when designing studies. ${ }^{28}$

These findings strongly suggest the need for further research on this topic. The overall goal of further research should include the combination of rehabilitation clinicians with rehabilitation researchers to discuss and problem solve the issue of the lack of applicability of research findings to clinical practice. Both sides need to be investigated: how can researchers design their research to be more applicable to clinical care and how can clinicians better utilize the current research literature to inform their treatment plans.

\section{Strengths}

The utilization of qualitative methodology within this investigation allowed each participant to provide an indepth perspective that is not possible with quantitative survey research. Although the clinician participants were quite diverse, common experiences emerged, highlighting the consistency of experiences for rehabilitation clinicians. Saturation was achieved through the interview process, which indicates that an adequate number of interviews were conducted.

\section{Limitations}

A limitation of this study was that we were only able to recruit male physiatrists and female RCs, PTs, and OTs. Therefore, perspectives from female physiatrists and male RCs, PTs, and OTs were not included. While respondents included rehabilitation clinicians of four different specialties, an uneven number of each type was included in our study; thus, each clinician type was not equally represented in the data. In addition, other important characteristics of the clinicians could affect the way in which they respond to the questions. For example, age and professional experience are two variables that might have an impact on the access and utilization of research findings. Future research should take these factors into consideration. There was a large diversity of individuals included in this investigation (i.e., different working conditions, involved in different levels of research), and this diversity of individuals could have negatively impacted our findings. However, we found relatively consistent findings, both across and within rehabilitation clinician types, and are therefore confident that the findings are relatively robust to the diversity of individuals. 


\section{Conclusion}

The utilization of EBP needs to be increased within the field of rehabilitation. The insights gained from the participants in the current study highlight the need for researchers to be aware of the applicability of their research design and findings. In addition, access to the latest research findings is still a barrier to implementation of EBP. Future research should consider focus group investigations combining clinicians and researchers to discuss solutions for these issues.

\section{Acknowledgment}

This work was funded by the NIDILRR and is operated by the AIR under grant number 90DP0012-01-00.

\section{Author contributions}

All authors contributed toward data analysis, drafting and critically revising the paper and agree to be accountable for all aspects of the work

\section{Disclosure}

The authors report no conflicts of interest in this work.

\section{References}

1. Estabrooks C, Floyd J, Scott-Findlay S, O’Leary K, Gushta M. Individual determinants of research utilization: a systematic review. $J A d v$ Nurs. 2003;43(5):506-520.

2. Haug JD. Physicians' preferences for information sources: a metaanalytic study. Bull Med Libr Assoc. 1997;85(3):223-232.

3. Kloda L, Bartlett J. Clinical information behavior of rehabilitation therapists: a review of the research on occupational therapists, physical therapists, and speech-language pathologists. J Med Libr Assoc. 2009;97(3):194-202.

4. Rosenberg W, Donald A. Evidence based medicine: an approach to clinical problem-solving. BMJ. 1995;310(6987):1122-1126.

5. Mensik JS. Understanding research and evidence-based practice: from knowledge generation to translation. J Infus Nurs. 2011;34(3):174-178.

6. Menon A, Korner-Bitensky N, Kastner M, McKibbon KA, Straus S. Strategies for rehabilitation professionals to move evidencebased knowledge into practice: a systematic review. J Rehabil Med. 2009;41(13):1024-1032.

7. Kloda L, Bartlett J. Formulating answerable questions: question negotiation in evidence-based practice. $J$ Can Health Libr Assoc. 2014;34(2):55-60.

8. Rappolt $\mathrm{S}$, Tassone M. How rehabilitation therapists gather, evaluate, and implement new knowledge. J Contin Educ Health Prof. 2002;22(3): $170-180$.

9. Zidaraov D, Thomas A, Poissant L. Knowledge translation in physical therapy. Disabil Rehabil. 2013;35(18):1571-1577.
10. Cicerone KD. Evidence-based practice and the limits of rational rehabilitation. Arch Phys Med Rehabil. 2005;86(6):1073-1074.

11. Bennett S, Tooth L, McKenna K, et al. Perceptions of evidence-based practice: a survey of Australian occupational therapists. Aust Occup Ther J. 2003;50(1):13-22.

12. Jette DU, Bacon K, Batty C, et al. Evidence-based practice: beliefs, attitudes, knowledge, and behaviors of physical therapists. Phys Ther. 2003;83(9):786-805.

13. Jansen L, Rasekaba T, Presnell S, Holland AE. Finding evidence to support practice in allied health: peers, experience, and the internet J Allied Health. 2012;41(4):154-161.

14. Heiwe S, Kajermo KN, Tyni-Lenné R, et al. Evidence-based practice: attitudes, knowledge and behaviour among allied health care professionals. Int J Qual Health Care. 2011;23(2):198-209.

15. Upton D, Stephens D, Williams B, Scurlock-Evans L. Occupational therapists' attitudes, knowledge, and implementation of evidence-based practice: a systematic review of published research. Br J Occup Ther. 2014;77(1):24-38

16. MacEwan Dysart A, Tomlin GS. Factors related to evidence-based practice among U.S. Occupational Therapy Clinicians. Am J Occup Ther. 2002;56(3):275-284.

17. Maher CG, Sherrington C, Elkins M, Herbert RD, Moseley AM. Challenges for evidence-based physical therapy: accessing and interpreting high-quality evidence on therapy. Phys Ther. 2004;84(7):644-654.

18. Pollock AS, Legg L, Langhorne P, Sellars C. Barriers to achieving evidence-based stroke rehabilitation. Clin Rehabil. 2000;14(6): 611-617.

19. O'Reilly CA 3rd. Variations in decision makers' use of information sources: the impact of quality and accessibility of information. Acad Manage J. 1982;25(4):756-771.

20. Maki DR, Tarvydas VM, editors. The Professional Practice of Rehabilitation Counseling. New York, NY: Springer Publishing Company; 2011.

21. Rubin H, Rubin I. Qualitative Interviewing: The Art of Hearing Data. 2nd ed. Thousand Oaks, CA: Sage; 2005.

22. Gale NK, Heath G, Cameron E, Rashid S, Redwood S. Using the framework method for the analysis of qualitative data in multi-disciplinary health research. BMC Med Res Methodol. 2013;13:117.

23. Creswell JW. Research Design: Qualitative, Quantitative, and Mixed Methods Approaches. Thousand Oaks, CA: Sage; 2013.

24. Ritchie J, Lewis J, Nicholls CM, Ormston R, editors. Qualitative Research Practice: A Guide for Social Science Students and Researchers. 2 ed. London: Sage Publications Ltd; 2013.

25. Schreiber J, Downey P, Traister J. Academic program support for evidence-based practice: a mixed-methods investigation. $J$ Phys Ther Educ. 2009;23(1):36-43.

26. Moore JL, Raad J, Ehrlich-Jones L, Heinemann AW. Development and use of a knowledge translation tool: the rehabilitation measures database. Arch Phys Med Rehabil. 2014;95(1):197-202.

27. Levac D, Glegg SMN, Camden C, Rivard LM, Missiuna C. Best practice recommendations for the development, implementation, and evaluation of online knowledge translation resources in rehabilitation. Phys Ther 2015;95(4):648-662.

28. Chau T, Moghimi S, Popovic MR. Knowledge translation in rehabilitation engineering research and development: a knowledge ecosystem framework. Arch Phys Med Rehabil. 2013;94(1 suppl):S9-S19.
Journal of Multidisciplinary Healthcare

\section{Publish your work in this journal}

The Journal of Multidisciplinary Healthcare is an international, peerreviewed open-access journal that aims to represent and publish research in healthcare areas delivered by practitioners of different disciplines. This includes studies and reviews conducted by multidisciplinary teams as well as research which evaluates the results or conduct of such teams or health care processes in general. The journal covers a very wide range of areas and welcomes submissions from practitioners at all levels, from all over the world. The manuscript management system is completely online and includes a very quick and fair peer-review system. Visit http://www.dovepress.com/ testimonials.php to read real quotes from published authors. 